\title{
EDUCAÇÃO PATRIMONIAL E ENSINO DE HISTÓRIA NA ILHA DO MEL
}

\author{
HERITAGE EDUCATION AND HISTORY OF EDUCATION IN ILHA DO MEL
}

Evandro Cardoso do Nascimento ${ }^{1}$

\begin{abstract}
RESUMO: A proposta deste artigo é apresentar experiências de educação patrimonial na Ilha do Mel - Paranaguá/PR desenvolvidas com alunos do $6^{\circ}$ ano do ensino fundamental do Colégio Estadual Lucy Requião de Mello e Silva. Neste contexto, a educação histórica surge como referencial teórico e metodológico que orienta tais investigações e possibilita a utilização do patrimônio como fonte primária para as aulas de História. Partindo das preposições de Jörn Rüsen (2001), Peter Lee (2003) e Isabel Barca (2004) este trabalho busca investigar a relação que a educação patrimonial tem com a educação histórica e apresentar as experiências da pesquisa empírica. Tal investigação revela que o patrimônio, quando enquadrado na perspectiva da educação histórica, contribui para o desenvolvimento da consciência histórica dos alunos.
\end{abstract}

Palavras-Chave: Consciência Histórica. Narrativa Histórica. Aula Oficina.

\begin{abstract}
The purpose of this paper is to present heritage education experiences in Ilha do Mel - Paranaguá/PR developed with students of the 6th year of basic education of State College Lucy Requião de Mello e Silva. In this context, the Historical Education emerges as a theoretical and methodological body that guides such investigations and allows the use of heritage as a resource for the lessons of history. Based on the theories of Jörn Rüsen (2001), Peter Lee (2003) and Isabel Barca (2004) this work investigates the relationship that heritage education has with the Historical Education and present the experiences of empirical research. This research shows that the heritage, when viewed in the context of History Education, contributes to the development of historical consciousness of the students.
\end{abstract}

Keywords: Historical Consciousness. Historical Narrative. Lesson Workshop.

\footnotetext{
1 Professor Auxiliar do curso de História da Universidade Estadual do Paraná, Setor Litoral, mestrando em Desenvolvimento Territorial Sustentável.
} 


\section{Introdução}

Este artigo é resultado de investigações sobre o ensino de História e apresenta algumas relações teóricas e metodológicas entre o patrimônio e a educação histórica. Na era da patrimonialização, o tema do ensino de História tem granjeado espaço nas discussões sobre conscientização patrimonial e preservação da memória, revelando que o aprendizado histórico contribui para o reconhecimento e valorização do patrimônio. As pesquisas em educação histórica, por sua vez, têm desenvolvido novas abordagens e metodologias que possibilitam a utilização de inúmeros recursos, entre eles o patrimônio, para o desenvolvimento da consciência histórica dos alunos.

As relações entre patrimônio e educação histórica têm sido objeto de estudo de alguns pesquisadores contemporâneos, entre eles a professora Tânia Gayer Ehlke (Brasil), a pesquisadora Helena Pinto (Portugal), e a professora Regina Parente (Portugal), além de diversas pesquisas sobre educação patrimonial. Neste artigo, o objetivo maior é apresentar experiências de educação patrimonial na Ilha do Mel, e sua contribuição para o desenvolvimento da consciência histórica dos alunos.

Localizada no litoral sul do Brasil e pertencente ao município de Paranaguá, no estado do Paraná, a Ilha do Mel está separada do continente por aproximadamente 2.800 metros e encontra-se na entrada da Baía de Paranaguá (BRITEZ e MARQUES, 2005). 


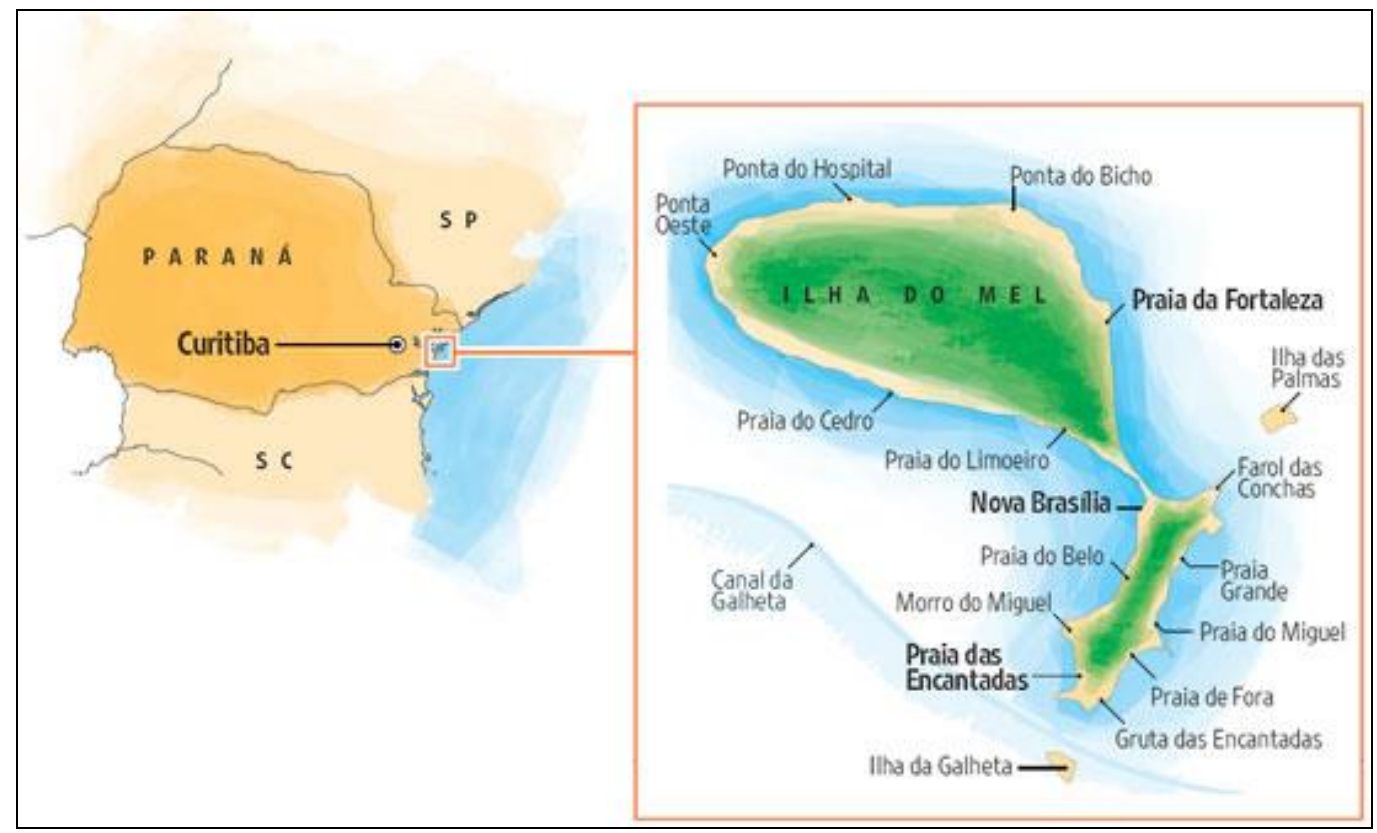

Figura 1: Mapa da Ilha do Mel.

Fonte: Editoria de Arte/Folha. Imagem Disponível em: http://pib.socioambiental.org/pt/noticias?id=71011 Acesso em: 12/01/2015.

A presença de sambaquis encontrados na Ilha do Mel revela que os primeiros ocupantes desse território foram de origem indígena. A colonização da ilha ocorreu, definitivamente, em 1767, quando o Rei Dom José I ordenou a construção da Fortaleza de Nossa Senhora dos Prazeres, com o intuito de proteger a região de Paranaguá. Neste período deu-se início a formação de vilarejos nos quais seus moradores cultivavam o modo de vida caiçara praticando a pesca e agricultura de subsistência. Em 1872, Dom Pedro II ordenou a construção do Farol das Conchas com o objetivo de orientar os navegadores que adentravam a baía (IPHAN, 2012).

A riqueza patrimonial do local escolhido para a pesquisa possibilitou maior contato dos alunos com o patrimônio. A escola escolhida oferece às comunidades as séries finais do ensino fundamental e ensino médio.

A pesquisa foi fundamentada a partir de conceitos teorizados por Pierre Bourdieu (2009), poder simbólico; Jörn Rüsen (2001), consciência histórica e narrativa histórica; Peter Lee (2003), empatia histórica; e Isabel Barca (2004), aula oficina. Assim, este trabalho encontra-se dividido em três seções sem contar a introdução e as considerações finais: primeiramente são tratados os aspectos 
conceituais de patrimônio e memória e sua relação com a educação histórica; na segunda parte são apresentadas as práticas de ensino desenvolvidas na pesquisa empírica; e por fim são apresentados os resultados da investigação através da cognição histórica dos alunos, a qual é expressa em forma de narrativas escritas.

\section{Patrimônio e educação histórica: diálogos}

As investigações em educação histórica, desde o final da década de 1980, tem mostrado diversas maneiras e possibilidades de desenvolver a consciência histórica dos alunos em sala de aula. Essa consciência histórica é defina por Rüsen (2001) como um trabalho intelectual que orienta o homem no tempo a partir das suas interpretações do passado. Através disso, no Brasil, professores e pesquisadores tem desenvolvido didáticas e metodologias diversificadas em suas pesquisas sobre educação e em suas aulas de história; entre elas, o uso da canção (AZAMBUJA, 2013), da história em quadrinhos (FRONZA, 2012), do cinema (SOUZA, 2010), entre outras.

Considerando que, nos últimos anos o interesse pela valorização e preservação do patrimônio cultural tem ganhado espaço entre os historiadores, o patrimônio cultural e histórico pode ser mais um elemento a ser pensado como recurso didático para o desenvolvimento da consciência histórica dos alunos. Nesta seção intitulada diálogos será apresentada a relação entre patrimônio e educação histórica a partir de seus aspectos conceituais.

O patrimônio cultural é um termo que remete a um campo de análise extremamente amplo e que neste artigo é tratado em suas três categorias: material, imaterial e natural. O patrimônio cultural material é o mais conhecido, em que se incluem casarões, engenhos, igrejas e objetos de valor cultural e histórico. Para François Choay (2006), o patrimônio material é um monumento que possibilita a contemplação de um passado mergulhado no tempo e que se relaciona de forma singular com a memória coletiva. No patrimônio imaterial se incluem: bens intangíveis e/ou simbólicos os quais são produtos de manifestações mais populares como celebrações, lendas, saberes e danças. Nas 
discussões científicas, somente a partir da década de 1960 a cultura imaterial passou a ser objeto de investigação dos pesquisadores europeus (LE GOFF, 2003; CHOAY, 2006). No Brasil esta concepção foi adotada no final do século XX, a partir do processo de democratização política e, como consequência da sua diversidade cultural, a política brasileira voltada à preservação da imaterialidade ganhou destaque internacional (NASCIMENTO, 2013).

O patrimônio natural, para Ferreira (2011), é uma área natural caracterizada pela ocorrência de espécies endêmicas, por exemplo, a Floresta Atlântica, o Pantanal e as Praias. Sobre esta categoria de patrimônio há quem diga que este não é cultural. Porém, perspectivas mais recentes consideram o patrimônio natural como cultural na medida em que nos espaços naturais fluem acontecimentos que, durante os anos, configuram paisagens culturais. A paisagem da praia, por exemplo, como defende Ferreira (2011), não pode ocorrer sem um diálogo do natural com os aspectos culturais.

Apesar das singularidades de cada categoria há interdependência entre elas. Em um território as edificações materiais mesclam-se com as paisagens naturais e, as manifestações imateriais se reproduzem nestes espaços, ou seja, se tornam cada vez mais tênues os limites entre tais categorias e a não percepção de uma delas pode descaracterizar todas as outras.

Segundo o historiador Ricardo Oriá (1997), as categorias do patrimônio foram tradicionalmente separadas nas políticas de preservação e, durante muito tempo, representaram apenas uma memória nacional e elitista. Segundo Laurent Lévi-Strauss (2006), o patrimônio material ou pedra e cal esteve vinculado à cultura erudita e, o patrimônio imaterial vinculado à cultura popular. Já o patrimônio natural está relacionado às preocupações ecológicas.

Conceituar patrimônio é uma tarefa que exige uma seleção de abordagens, visto que o campo patrimonial é investigado por arquitetos, turismólogos, advogados, historiadores. Neste sentido, pretende-se explorar o conceito histórico de patrimônio e sua relação com a memória histórica.

A partir da Revolução Francesa a ideia de patrimônio se vincula à noção de monumento memorável, possibilitando a formação de uma unicidade da memória, onde se dá sentido ao que se quer lembrar (DE DECCA, 1992). Assim, 
"ter controle sobre o patrimônio é ter controle sobre a lembrança e sobre o processo de ocultamento" (MAGALHÃES, 2009, p. 35).

Este campo de poder onde o patrimônio está inserido, diz respeito a um terreno de dominação simbólica, que segundo Bourdieu possui um "poder invisível o qual só pode ser exercido com a cumplicidade daqueles que não querem saber que the estão sujeitos ou mesmo que o exercem" (BOURDIEU, 2009, p. 8). De acordo com este pensamento, a memória histórica, viva no patrimônio, pode ser entendida como formadora de identidade cultural, onde o patrimônio histórico está inserido e sofre os efeitos do poder simbólico exercido por grupos no poder.

O patrimônio é entendido como uma herança do passado e tem a função de alimentar a memória coletiva. Porém, sofreu inferências no processo de construção do estado nacional, e foi utilizado como uma ferramenta de poder pelas classes dominantes.

\begin{abstract}
Enfim, os suportes da memória coletiva, que sempre foram elementos principais da criação do sentimento de continuidade e de preservação das sociedades pré-industriais, foram paulatinamente destruídos e hoje o cidadão se sente cada vez mais mutilado em seus sentimentos coletivos com relação ao passado. (DE DECCA, 1992 apud MAGALHÃES, 2009, p. 36).
\end{abstract}

Nos últimos anos, devido ao processo de patrimonialização e democratização da cultura, o conceito de patrimônio tem se alargado, deixando o aspecto apenas material, ligado aos grandes monumentos, e aderindo aspectos naturais e imateriais. Assim, "o conceito de patrimônio ganha aspectos mais amplos que buscam melhor entender o universo sociocultural com relação à memória e identidade coletiva" (NASCIMENTO, 2011, p. 2).

Dentro desta nova perspectiva de patrimônio, a educação patrimonial se torna extremamente importante no processo de reconhecimento, valorização e preservação dos bens patrimoniais da sociedade, e a disciplina de História tem sua função neste processo: reconstruir o passado histórico.

A disciplina da História se utiliza do patrimônio enquanto fonte, capaz de fornecer informações do passado das sociedades sob as 
representações da memória coletiva. Neste sentido, a educação patrimonial ganha nova perspectiva, onde objetiva-se a reconstrução do passado por meio do patrimônio histórico. (NASCIMENTO, 2011, p. 5)

Reconhecendo o patrimônio como um recurso didático para as aulas de História, o mesmo além de possibilitar a reconstrução do passado histórico, pode contribuir "para a construção de sentidos de pertenças" (PINTO, 2009, p. 283). Isso valoriza a cultura local e promove a conscientização patrimonial dos alunos.

Em consonância com o pensamento de Irene Nakou (2001), a pesquisadora Helena Pinto (2009, p. 283), tratando da relação patrimônio-museu-escola, diz que no museu "o pensamento histórico dos alunos é estimulado, uma vez que se rodeiam de evidências materiais da vida de uma comunidade humana no passado" (PINTO, 2009, p. 283). Tais evidências materiais é privilégio dos museus, mas também são encontradas em outros espaços sociais.

Na educação histórica o patrimônio passa a ser entendido como um vestígio do passado, que está ligado à vida cotidiana da comunidade (PINTO, 2009, p. 285). Tal entendimento possibilita o trabalho, em sala de aula, com os conceitos de segunda ordem².

É neste âmbito que a Educação Histórica assume um papel fundamental, uma vez que pressupõe o desenvolvimento de competências essenciais para a construção de uma cidadania esclarecida, nomeadamente as capacidades de análise, de crítica e de argumentação, indispensáveis para lidar com a pluralidade de informação da sociedade hodierna (PINTO, 2009, p. 286).

Considerando que o objetivo fundamental da Educação Histórica é "a aquisição de uma consciência histórica para que os indivíduos possam se situar em relação aos seus ancestrais e a seus contemporâneos" (CERCADILHO, 2009, p. 9), o patrimônio além de ser um vestígio dos seus ancestrais, "pode gerar uma tomada de consciência que Ihes permita converterem-se também em seus defensores" (PINTO, 2009, p. 284).

\footnotetext{
2 "Conceitos de segunda ordem são os que se referem à natureza da História, como por exemplo explicação, interpretação, compreensão." (LEE, 2001, p. 20)
} 
A consciência patrimonial, neste sentido, vai ao encontro da consciência histórica, defendida por Rüsen (2001, p. 59) como "o trabalho intelectual realizado pelo homem para tornar suas intenções de agir conformes com a experiência do tempo", isto é, a consciência histórica orienta o homem no tempo e no espaço a partir da interpretação do passado.

Trata-se de um processo da consciência em que as experiências do tempo são interpretadas com relação às intenções do agir e, enquanto interpretadas, inserem-se na determinação do sentido do mundo e na auto-interpretação do homem, parâmetros de sua orientação no agir e no sofrer. (RÜSEN, 2001, p. 59)

Neste sentido, a consciência patrimonial não é apenas a ação preservacionista para com os vestígios do passado, mas é também o reconhecimento histórico do patrimônio e a interpretação deste no tempo, objetivando a formação de sentido à sua preservação no presente. Uma ação preservacionista que não se apropria da consciência histórica, corre o risco de se perder o sentido para a sociedade, pois a interpretação do passado é a geradora de sentido à vida prática no presente.

\section{Cognição histórica e fontes patrimoniais: "aula oficina"3}

Tendo a educação histórica como ponto de partida para o desenvolvimento da consciência histórica dos alunos, esta seção visa apresentar atividades que foram desenvolvidas na pesquisa empírica. Tal pesquisa foi realizada no Colégio Estadual Lucy Requião de Mello e Silva, localizado na Ilha do Mel - Paranaguá PR. Com o objetivo de delimitar a pesquisa e para poder inserir a educação patrimonial no currículo regular de História, buscou-se trabalhar apenas com o 60 ano, visto que a proposta curricular do Estado do Paraná para esta série propõe como conteúdo básico três temáticas em específico: a experiência

\footnotetext{
${ }^{3}$ Aula Oficina é o modelo de aula em que "o aluno é efetivamente visto como um dos agentes do seu próprio conhecimento, as atividades das aulas, diversificadas e intelectualmente desafiadoras, são realizadas por estes e os produtos daí resultantes são integrados na avaliação." (BARCA, 2004, p. 131)
} 
humana no tempo, onde o patrimônio histórico-cultural surge como um representante do passado no presente; os sujeitos e suas relações com o outro no tempo, que pode ser trabalhado o processo de valoração do patrimônio pelas comunidades na história; e as culturas locais e a cultura comum, em que o patrimônio surge como um criador de identidades culturais.

Quando o projeto foi implantado na escola, o $6^{\circ}$ ano contava com um total de 15 alunos, visto tratar de uma comunidade pequena. $06^{\circ}$ ano " $A$ ", localizado na comunidade de Nova Brasília, estava com 7 alunos matriculados, e o $6^{\circ}$ ano "B", localizado em Encantadas contava com 8 aluno matriculados. O número reduzido de alunos facilitou o trabalho do professor, e a inserção no currículo regular da escola possibilitou tempo hábil para o projeto.

Seguindo a proposta metodológica de Aula Oficina, apresentada pela pesquisadora Isabel Barca (2004), o trabalho com os alunos em sala de aula foi dividido em várias etapas, sendo elas: elaboração de um inventário do patrimônio feito pelos alunos; seleção dos patrimônios mais significativos para eles; escritas de narrativas históricas utilizando tais bens como fonte (conhecimentos prévios); pesquisa de campo com registros fotográficos, entrevistas e práticas culturais; intervenção pedagógica sobre a construção e seleção do patrimônio histórico e história local; e atividade de metacognição histórica, onde os alunos produziram narrativas históricas e foram avaliados os níveis de consciência e compreensão histórica.

$\mathrm{Na}$ primeira fase do projeto os alunos elaboraram um inventário do patrimônio cultural da Ilha do Mel, nesta etapa os grupos (divididos em temas) fizeram um levantamento do patrimônio; em clima de competição entre as equipes, o resultado foi um número total de 44 bens patrimoniais de caráter natural, 44 bens de caráter imaterial e 88 bens de caráter material. Detalhe, neste levantamento os alunos tiveram a liberdade de inventariar todos os bens que julgassem patrimônio, independente se são ou não tombados.

Para possibilitar o trabalho com fontes históricas patrimoniais em sala de aula fez-se necessário a seleção de apenas alguns bens, visto que o trabalho com todos seria impossível. Para tanto, partiu-se para a segunda fase do projeto que foi a seleção dos bens mais significativos, onde cada aluno teve a 
oportunidade de eleger três bens que julgasse mais importante dentre todos; o resultado está exposto no Quadro 1: Seleção dos Bens Patrimoniais mais Significativos.

Quadro 1: Seleção dos Bens Patrimoniais mais Significativos

\begin{tabular}{|c|c|c|c|}
\hline $\begin{array}{l}\text { Aluno } \\
\text { (a) }\end{array}$ & \multicolumn{3}{|c|}{ Bens Patrimoniais Selecionados } \\
\hline Nathali & $\begin{array}{c}\text { Praça de } \\
\text { Alimentação }\end{array}$ & Colégio Lucy & $\begin{array}{l}\text { Pousada Bob Pai Bob } \\
\text { Filho }\end{array}$ \\
\hline Francisco & Farol das Conchas & Fortaleza & Pousada Caraguatá \\
\hline Leonardo & Postinho de Saúde & Trapiche & Pousada Luz Verde \\
\hline Gabriel & Gruta & Praia do Miguel & Morro do Sabão \\
\hline Lucas & Praia da Boia & Ilha do Cará & Morro da Cruz \\
\hline Isadora & Lenda da Sereia & História do Saci & Festa da Tainha \\
\hline Graziela & Lenda da Fortaleza & História do Vô Lavínio & Fandango \\
\hline Danilo & Capoeira & Lenda do Soldado & Canoa de um pau só \\
\hline James & Lenda da Sereia & $\begin{array}{c}\text { Técnica de fazer redes } \\
\text { de pesca }\end{array}$ & $\begin{array}{l}\text { Lenda do padre sem } \\
\text { cabeça }\end{array}$ \\
\hline Alex & Chapéu de Palha & Festa da Tainha & $\begin{array}{l}\text { Lenda do Caminho do } \\
\text { Arrepio }\end{array}$ \\
\hline Verônica & Biblioteca do Forte & Cemitério & $\begin{array}{c}\text { Casa Antiga da Ponta } \\
\text { Oeste }\end{array}$ \\
\hline Jhonny & Fortaleza & Rádio do Farol & $\begin{array}{c}\text { Igreja Antiga } \\
\text { (escravos) }\end{array}$ \\
\hline Larissa & Farol das Conchas & Mirante & Mercado Mergulhão \\
\hline João & $\begin{array}{l}\text { Salão do Vô } \\
\text { Diamantino }\end{array}$ & $\begin{array}{l}\text { Salão Comunitário } \\
\text { (SEIM) }\end{array}$ & $\begin{array}{l}\text { Trapiche de } \\
\text { Encantadas }\end{array}$ \\
\hline Jorge & Mares de Brasília & Manguezais & $\begin{array}{c}\text { Fauna e Flora da Ilha } \\
\text { do Mel }\end{array}$ \\
\hline
\end{tabular}

Fonte: Alunos do $6^{\circ}$ ano do Colégio Estadual Lucy Requião de Mello e Silva.

Depois de eleito os bens patrimoniais mais significativos na visão os alunos, foi solicitada, via questionário, uma justificativa para a seleção destes bens em detrimento aos outros. Nesta fase os alunos foram questionados sobre o passado do patrimônio que eles escolheram, foi solicitado que eles realizassem mais um filtro, isto é, dentre os três bens patrimoniais anteriormente selecionados, deveriam escolher apenas um e responder (de forma dissertativa) a seguinte questão: O que você sabe sobre a História deste patrimônio? Dos 15 alunos questionados 4, não responderam, 4 não fizeram referência ao tempo histórico, e 7 fizeram referência ao passado em suas narrativas. 
Dentre os que escreveram, porém não se reportaram ao passado, as narrativas se basearam em dados contemporâneos e descritivos, voltados à funcionalidade do bem escolhido, isso é percebido na narrativa do aluno Alex (60 A) ao escrever sobre a Festa da Tainha (patrimônio imaterial): "A Festa da Tainha é muito legal, neste ano vai muita gente para a festa que vai ter muita Tainha assada e bingo" (Alex, $6^{\circ} \mathrm{A}$ ).

Dentre os alunos que fizeram referência ao passado muitos procuraram mostrar as lendas e contos que fazem parte da tradição local, exemplo disso é a narrativa do aluno Gabriel ( $\left.6^{\circ} \mathrm{B}\right)$ que escreveu sobre a História da Gruta:

\footnotetext{
Os antigos diziam que lá na gruta tinham sereias, uma vez os pescadores foram pescar lá à noite e falaram que as sereias os encantaram com uma música [...]. Meu pai falou que quando tinha 15 anos foi pescar lá à noite com o meu avô e escutaram urros da sereia (Gabriel, $6^{\circ}$ B).
}

Percebe-se que ao ser questionado sobre a História da Gruta (patrimônio natural) o aluno faz referência ao passado e utiliza como evidência o seu pai, seu avô e os antigos; também faz referência à data (pai, quando tinha 15 anos). A narrativa do Gabriel procura resgatar um passado lendário para fundamentar a importância e o valor histórico da Gruta de Encantadas.

Outro aluno que faz referência ao passado, porém não se utiliza de lendas, é o Lucas ( $\left.6^{\circ} \mathrm{B}\right)$; em sua narrativa sobre o Morro da Cruz (patrimônio natural), busca resgatar a origem do nome Morro da Cruz, segundo ele "Têm uma capela com fotos dos que morreram, por isso o nome: Morro da Cruz." (Lucas, 60 B). Tais respostas compõem os conhecimentos prévios dos alunos com relação à história local.

Seguindo o modelo proposto por Isabel Barca (2004) sobre o uso de fontes no ensino da história, partiu-se para a pesquisa de campo, onde os alunos foram em busca de fontes que viessem validar seus conhecimentos prévios. Nesta fase, os alunos realizaram pesquisas sob a orientação do professor, onde foram feitos registros fotográficos, entrevistas na comunidade e seleção de fontes a serem trabalhadas. Durante todo este processo os alunos desenvolveram senso crítico 
com relação aos seus próprios conhecimentos prévios, e entenderam a importância da fonte histórica enquanto evidência do passado.

Segundo Barca (2004) os alunos, na interpretação das fontes primárias precisam

[...] "ler" fontes históricas diversas - com suportes diversos, com mensagens diversas; cruzar as fontes nas suas mensagens, nas suas intenções, na sua validade; selecionar as fontes com critérios de objetividade metodológica, para confirmação ou refutação de hipóteses descritivas e explicativas. (BARCA, 2004, p. 132)

Esse contato com as fontes históricas desenvolveram nos alunos a consciência histórica, pois a vivacidade da evidência material propicia a eles maior empatia histórica ${ }^{4}$ com relação ao passado da comunidade. $O$ nível de compreensão histórica é expresso por meio de narrativas históricas, que segundo Rüsen:

[...] torna presente o passado, sempre em uma consciência de tempo na qual o passado, presente e futuro formam uma unidade integrada, mediante a qual, justamente, constitui a consciência histórica. [...] A narrativa histórica organiza essa relação estrutural das três dimensões temporais com representações de continuidade, nas quais insere o conteúdo experimental da memória, a fim de poder interpretar as experiências do tempo e abrir as perspectivas de futuro em função das quais se pode agir intencionalmente. (RÜSEN, 2001 p. 65).

Em seu processo de reconstrução do passado histórico, os alunos buscam no patrimônio explicações históricas para sua valorização, e tentam responder as seguintes perguntas: como era no passado, como é reconhecido na atualidade e qual a importância de sua preservação para as próximas gerações. Tais respostas são sistematizadas em narrativas históricas escritas pelos alunos e compõem a próxima seção deste artigo.

\footnotetext{
4 "a empatia histórica pode ser melhor entendida como uma realização, algo que acontece quando sabemos o que o agente histórico pensou, quais os seus objectivos, como entenderam aquela situação e se conectamos tudo isso o com o que aqueles agentes fizeram." (LEE, 2003, p. 20)
} 


\section{Metacognição e narrativa histórica: a consciência histórica dos alunos}

Entendendo que a consciência histórica é expressa por meio de narrativas, "ou seja, no ato de contar histórias, pois esta é uma forma coerente de comunicação e porque trata da identidade histórica tanto do comunicador como do receptor" (GEVAERD, 2009, p. 141), os alunos foram encarados como pesquisadores e produziram suas próprias narrativas sobre o passado.

Depois de realizada a pesquisa de campo, partiu-se para a intervenção pedagógica, onde foi proposta uma atividade de metacognição histórica. Nesta fase da pesquisa, os alunos-pesquisadores transcreveram as entrevistas gravadas em áudio na comunidade e tomaram-nas como fonte histórica para a construção de suas próprias narrativas sobre o passado do patrimônio e seu sentido atual. Isso foi possível apenas com o $6^{\circ} \mathrm{B}$ (Encantadas), pois não se teve tempo hábil para concluir a pesquisa com o $6^{\circ} \mathrm{A}$ (Brasília).

Sendo assim, 8 alunos participaram da fase final da pesquisa relatada neste artigo. A proposta foi que eles respondessem a mesma pergunta realizada no início do projeto: O que você sabe sobre a História deste patrimônio? Todas as narrativas históricas fizeram referência ao passado, isso já demonstra um avanço na consciência histórica dos alunos, pois nos conhecimentos prévios dos 15 apenas 7 alunos fizeram tal referência.

Das 8 narrativas, 4 fizeram referência às fontes primárias, isto é, às entrevistas realizadas na comunidade; a narrativa do Danilo (60 B) é um exemplo desta referência: "Segundo o Tio Chuvinha, antigamente aqui na Ilha do Mel era bem diferente, pois da Gruta até onde fica os navios era tudo praia, o Tio Chuvinha ia lá com o Vô Lavínio" (Danilo, 60 B).

Ao tratar sobre a "História da História do Vô Lavínio" a maior preocupação da pesquisa era que a aluna Graziela a confundisse com a "História do Vô Lavínio" e acabassem narrando a lenda da qual o Vô Lavínio é o personagem principal, porém a aluna surpreendeu:

A História do Vô Lavínio é contada na Ilha do Mel desde 1965, isto é, já faz 47 anos que é contada na comunidade [...] o projeto que nós estamos realizando é muito 
importante, pois faz com que essa história seja contada de geração para geração (Graziela, $6^{\circ}$ B).

Percebe-se na narrativa da Graziela ( $\left.6^{\circ} \mathrm{B}\right)$ que também é feita referência à data "desde 1965", isso ocorre em mais 2 narrativas: "o trapiche foi construído há uns 15 anos atrás" (Leonardo, $6^{\circ} \mathrm{B}$ ); "A pousada Caraguatá foi construída no ano de 2006". (Francisco, 60 B).

Dentre as 8 narrativas produzidas, 4 fazem uma relação entre o tempo passado e o tempo presente, estes alunos mostraram um nível de empatia muito bom, pois identificaram a representação que este patrimônio tinha no passado e o significado ou função dele no presente: "O Morro da Cruz tinha o nome de Montanha do Iapina [...] Segundo o Tete [entrevistado] além de ser muito bonito o Morro da Cruz é uma ponto para os pescadores espiar os cardumes de Tainha (Lucas, 60B).

As narrativas dos alunos revelam que o patrimônio cultural e histórico é uma ferramenta útil para o desenvolvimento da consciência histórica em sala de aula. Segundo a pesquisadora Tânia Gayer Ehlke (2008), o patrimônio [imaterial, no caso específico de sua pesquisa] na educação histórica contribui para consolidar as pesquisas sobre ensino de História, "porque estimula e eleva a identidade do aluno, pois permite que as suas crenças, os saberes guardados na família, na comunidade, sejam considerados e relativizados frente a outras experiências do passado e do presente." (EHLKE, 2008, p. 7).

$\mathrm{Na}$ comunidade de Encantadas na Ilha do Mel os alunos, ao serem estimulados a pesquisar sobre o patrimônio local, demonstraram empatia com relação ao passado histórico.

\section{Considerações finais}

A consciência patrimonial voltada à valorização, reconhecimento e preservação do patrimônio natural, material e imaterial é o objetivo maior da educação patrimonial. A consciência histórica voltada à orientação no tempo, significação da vida prática e à assimilação dos conceitos de segunda ordem, 
formam o objetivo da educação histórica. Assim, a consciência patrimonial não é apenas a ação preservacionista para com o patrimônio natural, material e imaterial, entendidos aqui com vestígios do passado, mas é também o reconhecimento histórico do patrimônio e a interpretação deste no tempo, objetivando a formação de sentido à sua preservação no presente.

Dentro desta perspectiva de patrimônio, a educação patrimonial se torna extremamente importante no processo de reconhecimento, valorização e preservação dos bens patrimoniais da sociedade, e a disciplina de História tem sua função neste processo: reconstruir o passado histórico.

A Educação Histórica, neste sentido, propõe uma educação patrimonial eficaz, onde os alunos buscam interpretar o passado histórico a partir do patrimônio, gerando assim uma identidade histórica e cultural.

Segundo Rüsen "a consciência histórica é, pois, guiada pela intenção de dominar o tempo que é experimentado pelo homem como ameaça de perder-se na transformação do mundo e dele mesmo." (RÜSEN, 2001, p. 60) A partir desta concepção, percebe-se que uma ação preservacionista que não se apropria da consciência histórica, corre o risco de se perder o sentido para a sociedade, pois a interpretação do passado é a geradora de sentido à vida prática no presente.

\section{Referências}

AZAMBUJA, L. Jovens alunos e aprendizagem histórica: perspectivas a partir da canção popular. 2013. Tese (Doutorado em Educação) - Universidade Federal do Paraná, Curitiba, 2013.

BARCA, I. Aula Oficina: do Projeto à Avaliação. In. Para uma educação de qualidade: Atas da Quarta Jornada de Educação Histórica. Centro de Investigação em Educação (CIED) Instituto de Educação e Psicologia, Universidade do Minho. Braga, 2004.

BOURDIEU, P. O poder simbólico. Tradução: Fernando Tomaz. 12 ed. Editora: Bertrand Brasil. Rio de Janeiro/RJ, 2009.

BRITEZ, R. M.; MARQUES, M. C. M. Caracterização Geral. In. MARQUES, M. C. M.; BRITEZ, R. M. História natural e conservação da Ilha do Mel. (Org.). Curitiba: Editora UFPR, 2005. 
CERCADILHO, L. [Prefácio] Aprender História: perspectivas da Educação Histórica. In. SCHMIDT, M. A. BARCA, I. Aprender História: perspectivas da educação histórica. Editora: Unijuí. Ijuí, 2009.

CHOAY, F. A alegoria do patrimônio. Tradução: Luciano Vieira Machado. 3 ed. Estação Liberdade: UNESP, São Paulo, 2006.

DE DECCA, 1992 apud MAGALHÃES, L. H. et al. Educação Patrimonial: da teoria à prática. Editora: Unifil. Londrina/PR, 2009.

EHLKE, T. G. Patrimônio Imaterial e Educação Histórica. Setor de EducaçãoDTPEN - Departamento de Teoria e Prática de Ensino. 2008. Disponível em: www.diaadiaeducacao.pr.gov.br. Acesso em: 18 de Setembro de 2008.

FERREIRA, F. N. Paisagens de Praia: o litoral como patrimônio (Rio Grande, XIXXX). In. SCHIAVON, C. G. B. Anais eletrônicos do I Seminário de História e Patrimônio: diálogos e perspectivas. EdifURG, Rio Grande/RS, 2011. p. 549-569.

FRONZA, M. A intersubjetividade e a verdade na aprendizagem histórica de jovens estudantes a partir das histórias em quadrinhos. 2012. Tese (Doutorado em Educação) - Universidade Federal do Paraná, Curitiba, 2012.

GEVAERD, R. T. F. Narrar: uma maneira de aprender História na sala de aula. In. SCHMIDT, M. A. BARCA, I. Aprender História: perspectivas da educação histórica. Editora: Unijuí. Ijuí, 2009.

LE GOFF, J. (1924). História e Memória. Tradução: Bernardo Leitão, et al. 5 ed. Editora da Unicamp. Campinas/SP, 2003.

LEE, P. "Nós fabricamos carros e eles tinham que andar a pé": compreensão das pessoas do passado. In. BARCA, I. (org.). Educação histórica e museus. CIED, Universidade do Minho. Braga, 2003.

Progressão da compreensão dos alunos em História. In. BARCA, I.

Perspectivas em educação histórica. Uminho. Braga, 2001.

LÉVI-STRAUSS, L. Patrimônio Imaterial e Diversidade Cultural: O Novo Decreto para a Proteção dos Bens Imateriais. In. IPHAN. Patrimônio Imaterial: O Registro do Patrimônio Imaterial. Brasília. 4 ed., 2006.

MAGALHÃES, L. H. et al. Educação Patrimonial: da teoria à prática. Editora: Unifil. Londrina/PR, 2009.

NAKOU, I. (2001), apud PINTO, H. O triângulo patrimônio-museu-escola: que relações com a Educação Histórica? In. SCHMIDT, M. A. BARCA, I. Aprender História: perspectivas da educação histórica. Editora: Unijuí. Ijuí, 2009.

NASCIMENTO, E. C. Educação Patrimonial: perspectivas da educação histórica. Ed. Do Autor, Matinhos/PR, 2013.

História, Patrimônio e Educação Escolar: diálogos e perspectivas. Anais do XXVI Simpósio Nacional de História. São Paulo/SP, 2011.

ORIÁ, R. Memória e ensino de história. In. BITTENCOURT, C. (org.). O saber histórico em sala de aula. São Paulo: Contexto, 1997. 
PINTO, H. O triângulo patrimônio-museu-escola: que relações com a Educação Histórica? In. SCHMIDT, M. A. BARCA, I. Aprender História: perspectivas da educação histórica. Editora: Unijuí. Ijuí, 2009.

RÜSEN, J. Razão histórica: teoria da história: os fundamentos da ciência histórica. Tradução de Estevão de Rezende Martins, Brasília: Editora Universidade de Brasília, 2001.

SOUZA, É. . de. O que o cinema pode ensinar sobre a história? Ideias de jovens alunos sobre a relação entre filmes e aprendizagem histórica. História \& Ensino, Londrina, v. 16, n. 1, p. 25-39, 2010.

Recebido em 05 de fevereiro de 2015. Aprovado em 25 de agosto de 2015. 